\title{
Gene-therapy death prompts broad civil lawsuit
}

One year since the death of a volunteer in a gene therapy clinical trial at the University of Pennsylvania (UP; Philadelphia, PA), a broadly framed wrongful death lawsuit has been brought against the university, two local hospitals with which it is associated, and its private sector biotechnology collaborator, Genovo (Sharon Hills, PA). The lawsuit was filed by the patient's father and uncle in mid September in the Philadelphia County Court of Common Pleas. It not only names several UP faculty members who were directly involved in its gene therapy program, but unusually also singles out a bioethicist on the faculty who advised them as well as university trustees and specific administrators for alleged negligence and conflicts of interest.

As a civil action, the lawsuit seeks to collect both compensatory and punitive damages in excess of $\$ 50,000$ on all of several claims that, besides wrongful death, include "assault and battery," "lack of informed consent," "infliction of emotional distress," and "fraud on the Food and Drug Administration." However, in the broad sweep of the lawsuit, it in effect demands higher standards for safety during such clinical trials, insists on more detail and candor when disclosing risks to volunteers who participate in them, and calls for sharply restricting the kinds of conflict of interest that would be permitted among corporate and university partners that undertake gene therapy and other high-risk clinical trials. The demands coincide with espousals from Greg Koski of the new federal Office for Human Research Protections (Washington, DC) of stronger standards, and the American Society of Gene Therapy's (Milwaukee, WI) recent adoption of similarly stringent standards as a way of minimizing conflicts of interest (Nat. Biotechnol. 18, 1029).

Jesse Gelsinger had a mild form of a rare inherited nitrogen metabolism disorder called ornithine transcarbamylase (OTC) deficiency. He died in September 1999 while participating in the phase I clinical trial that was testing an engineered adenovirus vector carrying a gene intended to correct the defect. UP principal investigator James Wilson and other members of the UP team attributed Gelsinger's death to an acute respiratory system collapse and subsequent multiorgan failure induced, at least in part, by his immune system's response to the engineered viral vector (Nat. Biotechnol. 18, 377, 2000; 18,143, 2000; 17, 1153, 1999).

The lawsuit claims that Gelsinger died because the members of the UP medical team and other defendants were "careless, negligent, and reckless" and that they failed to "properly and adequately evaluate [Gelsinger's] condi- tion and eligibility for the gene transfer trial." Moreover, it claims that the adenoviral vector that "ultimately caused the death" was "defective" and "unreasonably dangerous." Among other specific claims, it contends that Genovo and UP researchers "allowed vectors to sit and/or be stored on lab shelves for 25 months before being tested on animals, making them less potent than they could have been." Moreover, the way the vector was stored "may have resulted in underestimation of [its] potency in humans."

The lawsuit also takes sharp issue with the financial arrangements between UP and Genovo, as well as with the extent to which Wilson has been involved with that company, including the extent of his equity holdings. In addition to naming Wilson and other members of the team who administered vectors to volunteers, the lawsuit names William Kelley, a former dean of the UP Medical School, who along with Wilson holds a broad patent covering several fundamental aspects of gene therapy technology involving use of such vectors. "Dr Kelley, Genovo, and Dr Wilson all stood to gain financially from the successful use of [adenovirus] vectors," the lawsuit states. And, because the university took an equity stake in Genovo, it, too, "stood to gain financially." These arrangements may have contributed to the defendants' alleged failure to notify officials of the FDA of "adverse or unexpected events associated with...the study."

Although a UP committee said in early 1995 that there appeared to be one or more conflicts of interest surrounding these arrangements with Genovo, university administrators approved them and allowed Wilson and colleagues to hold equity positions in the compa- ny and to plan and conduct clinical experiments involving volunteers at UP facilities. The lawsuit claims that these conflicts of interest were not fully disclosed to either Gelsinger or his father and, further, that they led Wilson and his colleagues to understate the clinical experiment's risks and to misrepresent the efficacy to be expected from the procedures.

A remarkable element of this lawsuit is the extent to which it cites Arthur Caplan, director of the UP Bioethics Department, who is widely known for his outspoken views on a wide range of ethical issues in modern biomedicine. The lawsuit suggests without explicitly stating so that Caplan was subject to a conflict of interest because Wilson's department helped to fund Caplan's program. Yet the lawsuit also references public statements from Caplan to buttress some of its claims against the defendants. For example, it quotes him as saying that "if you cured anybody from a phase I gene therapy trial, it would be a miracle" and "there was never a chance that anybody would benefit from these experiments."

Meanwhile, its more pointed complaint is aimed at Caplan's intervention in the early planning of the OTC deficiency gene therapy clinical trials in which he helped to persuade Wilson and colleagues to conduct their experiments on adults rather than on newborn infants with a more serious form of this deficiency. Part of the reasoning was that such infants cannot give informed consent and that their parents may be too easily persuaded to enroll their seriously ill children in clinical trials that appear to offer such a novel way of combating a potentially deadly and certainly life-long condition.

Jeffrey L. Fox

\section{Taco dispute underscores need for standardized tests}

On October 12, Safeway (Pleasanton, CA) removed its home-brand taco shells from supermarket shelves after Genetic Engineering Food Alert (GEFA; Washington, DC), a coalition of seven anti-biotechnology groups, said traces of a GM corn not yet approved for human consumption had been found in the shells. The move follows that by Kraft Foods (Northfield, IL), which recalled all Taco Bell Home Originals taco shell products on September 22 after tests commissioned by GEFA suggested the presence of the same GM corn. It was the first time a product containing GM ingredients had been with- drawn in the US, and the episode sparked a flurry of demands for tightening of biotech regulations including discussions between members of congress and the FDA commissioner Jane Henney. However, there has been no risk to human health, and the incident only illustrates the need for standardized tests and the importance that EPA set thresholds for the accidental mixing of ingredients.

The corn in question, StarLink, has been genetically modified by Aventis CropScience (Lyon, France) to express the insecticidal protein Cry9C from Bacillus thuringiensis. It is currently approved for animal consumption, 